\title{
Effect of Surfactant type on the Characteristics and Bioactivity of Mesoporous Bioactive Glasses
}

\author{
Hediyeh Nejati Rad', Aliasghar Behnamghader ${ }^{1, *}$, Mojgan Bagheri', Masoud Mozafari ${ }^{2}$ \\ ${ }^{1}$ Nanotechnology and Advanced Materials Department, Materials and Energy Research Center (MERC), Tehran, Iran \\ ${ }^{2}$ Department of Tissue Engineering \& Regenerative Medicine, Faculty of Advanced Technologies in Medicine, \\ Iran University of Medical Sciences, Tehran, Iran
}

*Corresponding author: E-mail: behnamghader@yahoo.com

DOI: 10.5185/amlett.2020.081547

In this study, mesoporous bioactive glass $77 \mathrm{~S}$ was synthesized by sol-gel method using two different ionic and nonionic surfactants. Physical-chemical properties of synthesized Bioglass were studied using techniques include X-ray diffraction, scanning electron microscopy, nitrogen adsorption and Fourier transform infrared spectroscopy. The results showed that using nonionic and ionic surfactants increased specific surface area by 3 and 5 times, respectively. By determining the silicon release in three different temperatures, the activation energy values of Si-O-Si for sample with surface area of 161 and $94 \mathrm{~m}^{2} / \mathrm{g}$ were calculated $1 / 10$ and $1 / 5$ of control glass with surface area of $34 \mathrm{~m}^{2} / \mathrm{g}$. The $\mathrm{pH}$ of sample was evaluated in solutions buffered with TRIS. $\mathrm{pH}$ analysis results suggested a direct relation between surface area and $\mathrm{pH}$ changes, the greatest increase in $\mathrm{pH}$ was observed in the sample with the highest surface area. Moreover, the in vitro bioactivity test was also conducted in simulated body fluid (SBF) and formation of apatite layer was evaluated by scanning electron microscopy and X-ray diffraction after a day.

\section{Introduction}

During the last decades, the bone diseases and trauma have significantly increased. The need of artificial replacement which can be used to repair or reconstruct damaged part has always been the driving force behind the discovery and design of new biomaterial. As a result, using bone graft as a substitute for defective bones has attracted a lot of attention. In some cases, bioactive glasses are available for use due to their ability to attach to bone chemically [1-3]. Bioactive glasses play a fundamental role in bone graft field due to osteoconductive, osteoproductive and osteoinductive properties. Further, high biocompatibility, positive biological effects, as well as bonding and integrating with living bone have made bioactive glasses as one of the most interesting bone graft materials during recent years [4-6]. Bone-bonding ability of bioactive glasses is attributed to the formation and growth of a hydroxyl carbonated apatite (HCA) layer, which its composition is similar to mineral phase of bone. This similarity let bioactive glasses have strong interaction and integration with bone [52]. The hydroxyl carbonated apatite (HCA) layer is formed on the surface of glasses when they are soaked in simulated body fluid (SBF) or implanted in vivo [7]. Further, the mechanism of formation HA layer initiates with exchanging Alkali ions $\mathrm{Na}^{+}$or $\left.\mathrm{Ca}^{2+}\right)$ with $\mathrm{H}^{+}$from the solution or body fluids, formation of silanol groups $(\mathrm{SiOH})$, dissolution of the silica glass network and polymerization of silica gel film by poly-condensation of silanol groups. Subsequently an amorphous calcium phosphate layer develops within the silica-rich layer, and the HA layer crystallizes, producing a hydroxycabonate apatite (HCA) layer $[\mathbf{8 , 9 , 3 3 ]}$.
These reactions occur only through a few hours for highly bioactive glasses. Based on the above-mentioned stages, the degradation of ionic products, especially silica, can be considered as a sign of bioactivity of the bioglasses. In summary, the ability of bioactive glasses for formation of HA layer and tissue repair is related to their chemical composition and their textural properties such as porosity, pore volume, pore size, and pore structure, which play a role in releasing ion [11-14]. Mesoporous bioactive glasses (MBG) have attracted great attention due to their large surface area and their property during last 20 years [15]. Further, these materials can act as a drug carrier owing to their outstanding textural properties of mesoporous bioactive glasses [16-18-55].

To prepare MBG, the supramolecular chemistry has been combined into sol-gel process [19]. In this case, structure-directing agents play an important role in producing mesoporous structure. Under synthesis conditions, these molecules are self-organized into micelles, and linked to the hydrophilic part of silica precursors, which results in formation of a self-assembly mesophase [1]. Finally, after drying of the product, the surfactant is removed and a mesoporous structure with high surface area and porosity is obtained.

The present study aimed to investigate the effect of surfactant type on the textural properties and bioactivity of bioactive glass $77 \mathrm{~S}$. To this aim, an anionic surfactant, sodium dodecyl sulfate and a nonionic surfactant, Triton X100 were used to produce the mesoporous structure of glass 77S. Three mesoporous bioactive glass samples $77 \mathrm{~S}$ (including control sample without surfactant) in the system of $\mathrm{SiO}_{2}-\mathrm{P}_{2} \mathrm{O}_{5}-\mathrm{CaO}$ were synthesized and characterized to 


\section{Advanced Materials Letters www.vbripress.com/aml}

examine the effects of surfactant type on the specific characteristics of the synthesized samples.

\section{Experimental procedure}

\section{Materials}

Tetraethyl orthosilicate $\left(\mathrm{Si}\left(\mathrm{OC}_{2} \mathrm{H}_{5}\right)_{4}, \quad\right.$ TEOS) $\quad(99 \%$ from Aldrich), triethyl phosphate $\left(\mathrm{OP}\left(\mathrm{OC}_{2} \mathrm{H}_{5}\right)_{3}\right.$, TEP) (99.8\% from Aldrich), calcium nitrate tetrahydrate $\left(\mathrm{Ca}\left(\mathrm{NO}_{3}\right)_{2} .4 \mathrm{H}_{2} \mathrm{O}\right)$ (Applichem) were used as silicon, phosphorous, and calcium sources. The surfactants sodium dodecyl sulfate (SDS- $\mathrm{NaC}_{12} \mathrm{H}_{25} \mathrm{SO}_{4}$ ) (Merck) and triton $\mathrm{X}-100\left(\left(\mathrm{C}_{14} \mathrm{H}_{22} \mathrm{O}\left(\mathrm{C}_{2} \mathrm{H}_{4} \mathrm{O}\right)_{\mathrm{n}}(\mathrm{n}=9-10)\right)\right.$ (Merck) were used as structure directing agent. In addition, deionized water and ethanol (from Merck) were used as solvent and $0.1 \mathrm{~mol} \mathrm{~L}^{-1}$ nitric acid $\left(\mathrm{HNO}_{3}\right)$ were utilized as catalyst.

In order to measure $\mathrm{pH}$ variation through soaking, Trisbuffer solutions ( $\mathrm{pH}=5.3,7.4,9$ ) were prepared by using hydrochloric acid and Tris (hydroxymethyl) aminomethane (THAM)(Merck).

\section{Synthesis}

At the first step, the surfactant was dissolved in deionized water and nitric acid media at room temperature. Then, absolute ethanol, TEOS, TEP and $\mathrm{Ca}\left(\mathrm{NO}_{3}\right)_{2}$ were added, respectively. After the final addition, the solution was taken under stirring condition for 1 hour in order to complete the hydrolysis process. The solution was kept at $50^{\circ} \mathrm{C}$ overnight until the gel was formed and then the gel was dried at $120^{\circ} \mathrm{C}$. Finally, the dried gel was heated at $550^{\circ} \mathrm{C}$ for 1.5 hours to eliminate the residual nitrate and organic substances.

The synthesized samples in the presence of SDS and Triton-X100 were coded as BGS glass and BGT glass, respectively. The control sample, BGC, synthesized without using surfactant.

\section{Characterization of bioactive glasses}

Thermal behavior: The phase transitions were monitored by using differential thermal analysis (DTA) and thermal gravimetric analysis (TGA) in order to estimate the stabilizing and crystallization temperatures of the glasses. So, BÄHR 503 (Germany) instrument was employed and the glasses were heated up to $1000^{\circ} \mathrm{C}$ at a heating rate of $10^{\circ} \mathrm{C} / \mathrm{min}$.

Chemical structure and phase characterization: Powder $\mathrm{X}$-ray diffraction (XRD) patterns were recorded using Simens $\mathrm{X}$-ray diffractometer with $\mathrm{Cu}-\mathrm{K} \alpha$ radiation and $\mathrm{X}$-ray wavelength of $1.540 \AA$. Diffractometer operated at $20 \mathrm{kV}$ and $10 \mathrm{~mA}$ with the step size of 0.05 over the $2 \Theta$ ranged between $10-80^{\circ}$. Further, Fourier transform infrared spectroscopy (FTIR) were performed by using Spectrum RXI (USA). Bioactive glass powders were mixed with $\mathrm{KBr}$ powder and pressed into a disk suitable for measuring FTIR. Finally, the FTIR spectra were recorded from $4000 \mathrm{~cm}^{-1}$ to $400 \mathrm{~cm}^{-1}$.

Morphology characterization: Field emission scanning electron microscopy (FE-SEM) (Mira3-XMU) on gold- coated specimens was used to examine the morphological and textural features of the bioactive glasses.

N2 adsorption-desorption isotherms, surface area and pore size: The surface area of samples was calculated via the Brunauer-Emmett-Teller (BET) method and the pore size of samples was obtained from the maxima of the pore size distribution curve calculated by the Barrett- JoynerHalenda $(\mathrm{BJH})$ method by using Belsorp Miniц with nitrogen as an absorbent at $77 \mathrm{~K}$.

Ion release and in vitro cellular bioactivity: The ion solubility tests were first conducted at three different temperatures by soaking $100 \mathrm{mg}$ of bioactive glasses in $100 \mathrm{~mL}$ of Tris-buffer at $\mathrm{pH}$ 7.4. The silicon concentration was analyzed by coupled plasma atomic emission spectroscopy (ICP-OES) Vistra-Pro inductively. The ion solubility tests were carried out at room temperature by soaking of each bioactive glasses in Tris-buffer $(\mathrm{pH}=5.3$, 7.4 and 9). $\mathrm{pH}$ of the solutions was measured with $\mathrm{pH}$ meter (MA 235 Mettledo-Toledo) during the soaking period.

In vitro bioactivity test for BGS glass was performed by soaking the bulks prepared from BGS powder into simulated body fluid (SBF) at $37^{\circ} \mathrm{C}$ under stirring. After 1 , 10 and 20 days of soaking, the samples were removed and washed with distilled water.

\section{Results and discussion}

\section{Materials characterization}

Fig. 1 illustrates the XRD patterns of the samples BGC, BGS and BGT. As shown, no characteristic diffraction was observed in the pattern except for broad band observed at $2 \theta$ values in the range of $20-30$ o for the three samples which indicating that all the samples are amorphous. The broad band in the range of 20-30。 was also found in similar works $[38,39]$. This broad band is suggested to be due to high percentage of amorphous particles in the samples [40, 41].

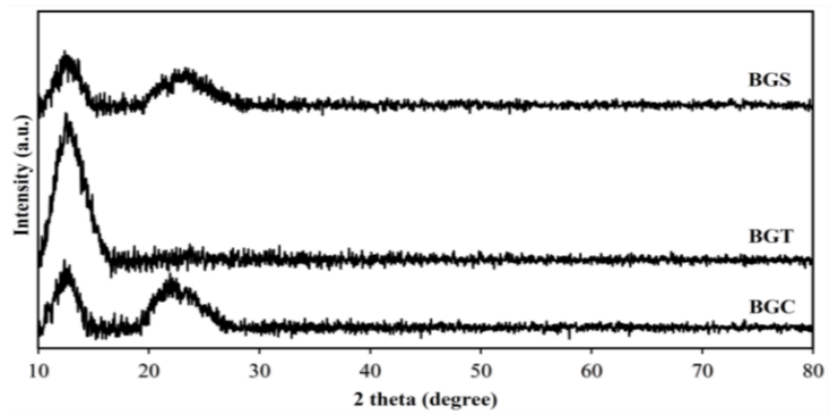

Fig. 1. The XRD pattern of samples BGC, BGT and BGS.

The simultaneous TG/DTA results of all samples are shown in Fig. 2. Based on the results, all the samples have similar weight loss regions. Weight loss at the first stage is about $10 \%$, $5 \%$ and $15 \%$ for the samples BGC, BGT and BGS, respectively, which can be related to the removal of chemically adsorbed water and correlated with an endothermic peak at $100-150^{\circ} \mathrm{C}$ in the DTA curve. Regarding BGT glass powder, Triton X-100 can be 


\section{Advanced}

oxidized by three steps, starting from $300^{\circ} \mathrm{C}$ to $500^{\circ} \mathrm{C}$ [26]. As observed in the TG curve of BGT, the most weight loss appears between $200-500^{\circ} \mathrm{C}$ due to the surfactant decomposition. TG results for BGS indicate that the residual weight fails to level off up to $1000^{\circ} \mathrm{C}$, due to the gradual decomposition of SDS surfactant in BGS [27]. Another endothermic peak at $500-550^{\circ} \mathrm{C}$ observed in sample BGS can be related to alkyl/nitrate groups. Large exothermic peak at $700^{\circ} \mathrm{C}$ which is more obvious in sample BGT are related to the crystallization of calcium-silicate phases in Bioglass [28].

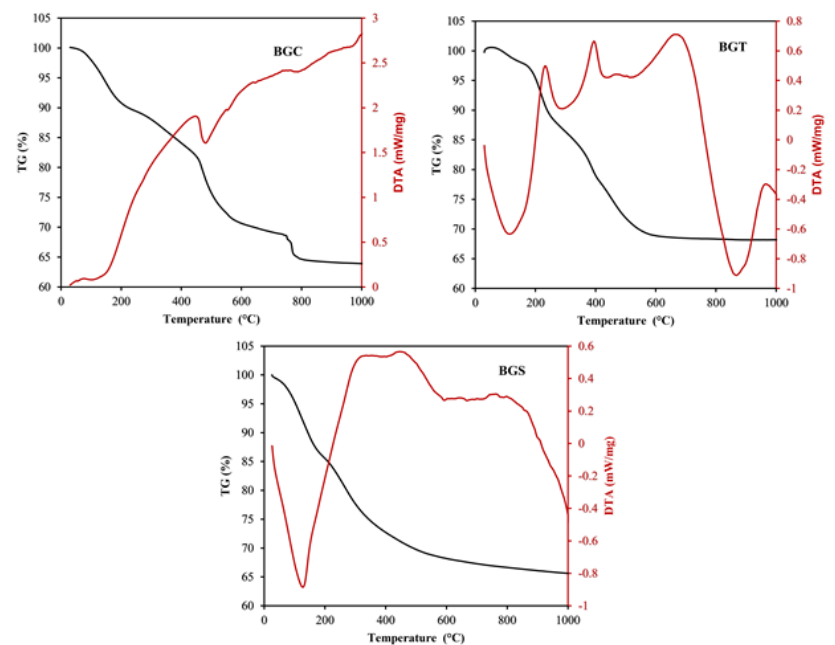

Fig. 2. TG/DTA curves of samples BGC, BGT and BGS.

Table 1 displays the textural parameters of BGC, BGT, and BGS. Based on the results, $S_{\mathrm{BET}}$ and pore volume increased in both of the samples synthesized with the surfactant due to the formation of mesopore structure after removing the surfactant through heat treatment. A remarkable increase was observed in $S_{\text {BET }}$ of BGS in which mesoporous structure is derived from SDS as a structuredirecting agent. In fact, the surface area relies on the chemical interaction between silica and surfactants [29]. Further, the interaction between ionic head group of surfactant (S) and inorganic precursors (I) is related to the electrostatic repulsion which is a driving force for the selfassembly of silica-micelle $[\mathbf{4 7 , 4 8}]$. Isoelectric point (pI) of silica is $\sim 2$ and silica species are the protonated, at a $\mathrm{pH}<2$ inorganic precursors would have positive charge $\left(\mathrm{I}^{+}\right)$and vice versa [49]. In case of using anionic surfactant, the possible synthetic rout should be follows as $\mathrm{S}^{-} \mathrm{I}^{+}$. Under acidic condition, interaction between positively charged silica oligomers and surfactant would be weak and might lead only lamellar and disordered mesostructured [50]. While, the chemical interactions in nonionic surfactants are based on hydrogen bonding due to electrically-neutral strategy and it follow $\mathrm{S}^{0} \mathrm{I}^{0}$ synthetic rout [42].

Fig. 3 illustrates the nitrogen adsorption isotherms and pore diameter distribution of samples BGC, BGT and BGS. The isotherm curve for all samples is identified as type IV according to IUPAC classification with Sharp inflections in the $\mathrm{P} / \mathrm{P}_{0}$, which is typically observed in mesoporous structures [56]. Sample BGC indicates an isotherm curve with H2-type hysteresis loop with smoothly increasing adsorption branch followed by a desorption branch step. Based on the hysteresis loop, the shape of pores would be ink bottle with wide bodies and narrow necks $[29,30]$. Further, both samples BGT and BGS show H3 hysteresis loops without any limitation to adsorb nitrogen at high $\mathrm{P} / \mathrm{P}_{0}$. The samples with $\mathrm{H} 3$ hysteresis loop might have plate-like particles with slit-shaped pores. A steep region so-called tensile strength at pressure range from 0.4-0.45 is observed in the hysteresis loop [31].

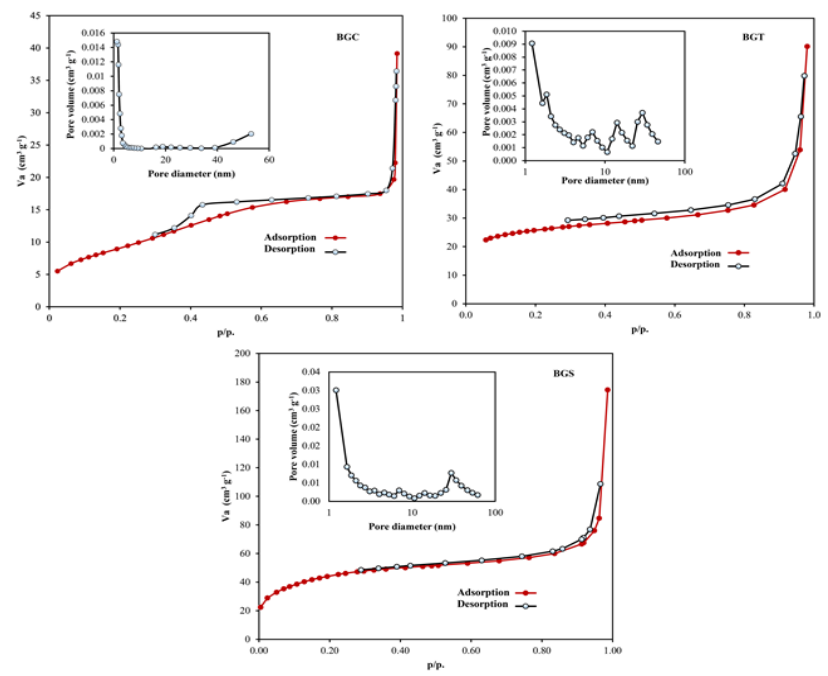

Fig. 3. $\mathrm{N}_{2}$ adsorption/desorption isotherms of samples BGC, BGT and BGS.

Table 1. Texture properties of the bioactive glasses.

\begin{tabular}{lccc}
\hline Sample & S $_{\text {BET }}\left(\mathbf{m}^{2} / \mathbf{g}\right)$ & Pore size $(\mathbf{n m})$ & Pore volume $\left(\mathbf{c m}^{\mathbf{3}} / \mathbf{g}\right)$ \\
\hline BGC & 34 & 7.1 & 0.03 \\
BGT & 94 & 5.9 & 0.11 \\
BGS & 161 & 6.7 & 0.21 \\
\hline
\end{tabular}

Fig. 4 displays the FTIR spectra of BGC, BGT and BGS in the $400-4000 \mathrm{~cm}^{-1}$. The silica vibrations at 456, 796 and $1080 \mathrm{~cm}^{-1}$ can be assigned to Si-O-Si bending, Si-O-Si symmetric stretching and $\mathrm{Si}-\mathrm{O}-\mathrm{Si}$ asymmetric stretching modes, respectively $[\mathbf{3 2 , 3 3}]$. P-O be nding band of $\mathrm{PO}_{4}{ }^{3-}$ group is observed at $606 \mathrm{~cm}^{-1}$ and $1260 \mathrm{~cm}^{-1}$ more, the band at $1673 \mathrm{~cm}^{-1}$ and the small peak at $3740 \mathrm{~cm}^{-1} \mathrm{can}$ be related to the adsorbed water at the surface of glasses and silanol groups, respectively [33]. All the samples indicated similar characteristics of the absorption bands.

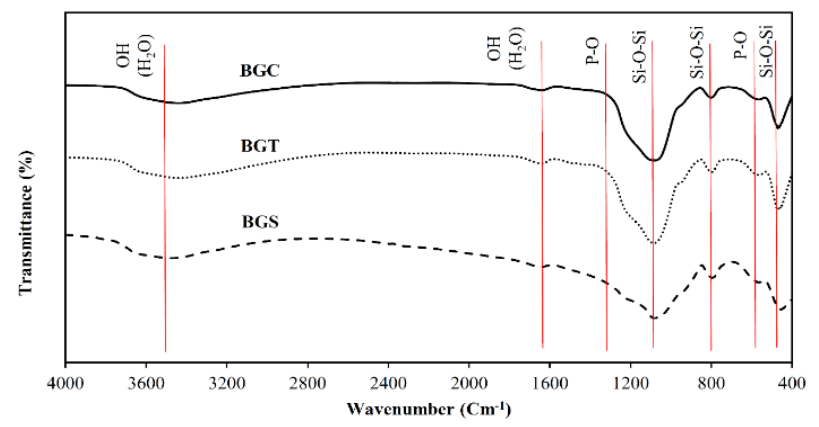

Fig. 4. The FT IR spectra of samples BGC, BGT and BGS. 


\section{Advanced Materials Letters www.vbripress.com/aml}

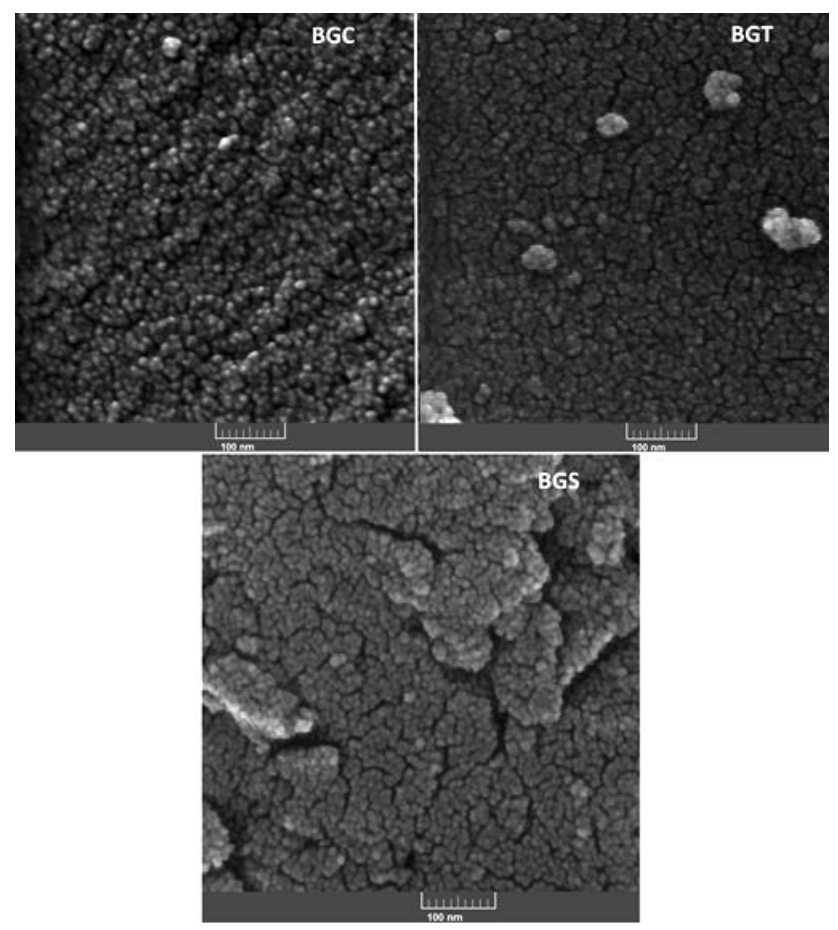

Fig. 5. SEM micrographs of samples BGC, BGT and BGS.

The FE-SEM images of sample BGC, BGT and BGS are shown in Fig. 5. Based on the results, all of the samples are porous although sample BGS has more porosity, compared to BGC and BGT, which is in agreement with BET results. It is indicated that micelles grow as the same time as the silica walls are built around the micelles so porosity appears when the speed of growing of micelles and building of silica walls are the same [43].

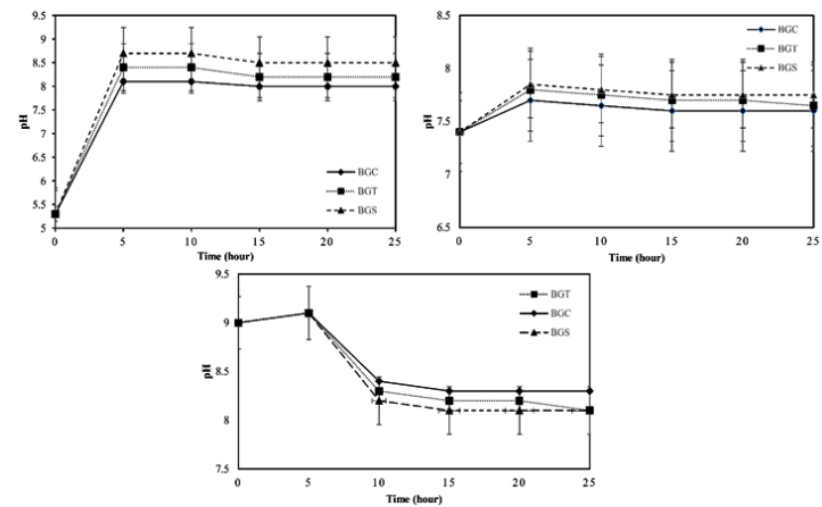

Fig. 6. $\mathrm{pH}$ of samples BGC, BGT and BGS dissolution in different condition by the time.

\section{Dissolution tests}

Fig. 6 displays the results of dissolution experiment in different conditions (acidic, neutral and basic). As shown, an increase in $\mathrm{pH}$ is observed for all samples in the initial period of dissolution due to the exchange between $\mathrm{Ca}^{2+}$ and $\mathrm{H}^{+}$ions in solution. According to Hench's theory, the formation of $\mathrm{Si}-\mathrm{OH}$ from $\mathrm{Si}-\mathrm{O}-\mathrm{NB}$ after releasing $\mathrm{Ca}^{2+}$ results in increasing $\mathrm{pH}$ as follows [33]:

$$
\mathrm{Si}-\mathrm{O}-\mathrm{Ca}+\mathrm{H}^{+}+\mathrm{OH}^{-} \rightarrow \mathrm{Si}-\mathrm{OH}+\mathrm{Ca}^{+}+\mathrm{OH}^{-}
$$

Then, the second stage of Hench's theory occurs after an increase in $\mathrm{pH}$. The reason for decreasing in $\mathrm{pH}$ for all samples can be explained by the hydrolysis of $\mathrm{Si}-\mathrm{O}-\mathrm{Si}$ through the dissolution of $\mathrm{Si}(\mathrm{OH})_{4}$ which is facilitated by increasing the $\mathrm{pH}$ in the first stage [34].

$$
2(\mathrm{Si}-\mathrm{O}-\mathrm{Si})+2\left(\mathrm{OH}^{-}\right) \rightarrow \mathrm{Si}-\mathrm{OH}+\mathrm{Si}-\mathrm{OH}
$$

Regarding higher surface area of sample BGS, more $\mathrm{pH}$ changes has been recorded in that sample in comparison with samples BGC and BGT. In fact, the formation of $\mathrm{Si}$ $\mathrm{OH}$ and the silicon release is easier in the glasses with higher surface area. Hence, the glasses with higher surface area tend to show the highest change in $\mathrm{pH}$ due to a better interaction between glass and buffer solution. It is suggested by Tabia et al. [44] that bioactive glasses with higher surface area are more prone to dissolution and have more intense ionic exchange between their surface and the surrounding medium. As a result, a significant increase of the $\mathrm{pH}$ is expected in bioactive glasses with high surface area.

In the basic condition, a decrease in $\mathrm{pH}$ is observed after 20 hours of reaction because of precipitating carbonates and calcium phosphates. The same result detected by Cerruti et al., [46]. At $\mathrm{pH}>8$, the reactions are as follow:

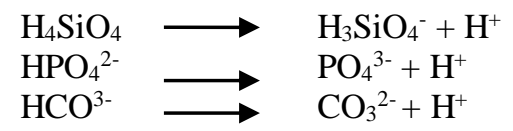

Lo'pez-Noriega et al., [45] reached the same pattern for $\mathrm{pH}$ changes in the similar work.

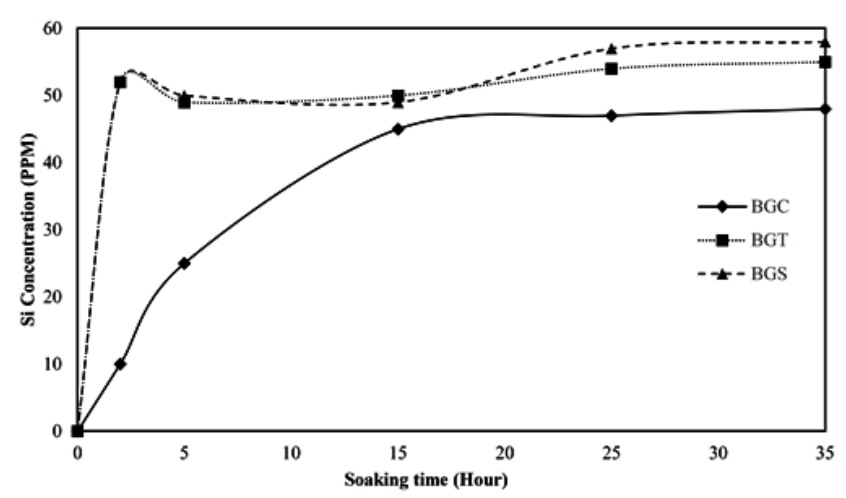

Fig. 7. Silicon release from samples BGC, BGT and BGS after 35 hours soaking in buffer with $\mathrm{pH}$ of 7.4.

Fig. 7 demonstrates the amounts of silicon released from the glasses in buffer with $\mathrm{pH}$ of 7.4 at room temperature. As shown in Fig. 7, the highest release of silicon was observed in the sample BGS glass after $35 \mathrm{~h}$. Moreover, a significant difference was observed during invitro experiments among the glasses because of their surface area. The bioactive glasses of BGS and BGT displayed a rapid silicon release during the first $5 \mathrm{~h}$ and then followed by a plateau until the end of test. Further, the amount of released silicon from the sample BGC was less 


\section{Advanced Materials Letters www.vbripress.com/aml}

than the treated samples with surfactants (BGS and BGT). These differences in silicon release between treated and non-treated samples can be attributed to their surface areas. In order to calculate activation energy (Ea), the silicon release test was conducted at 20,35 and $60^{\circ} \mathrm{C}$ for a duration of $6 \mathrm{~h}$. The value of activation energy calculated via the following equation (6) as ionic diffusion model [34].

$$
\mathrm{Ln}[\mathrm{Si}]=\mathrm{Ln}[\mathrm{SiO}]-\mathrm{Ea} / \mathrm{KT}
$$

The activation energy for BGS glass is equal to $0.05 \mathrm{eV}$, which is lower than two other samples. BGC glass indicates the highest $\mathrm{Ea}, 0.53 \mathrm{eV}$, which is ten times higher than BGS (0.05 ev) and Ea sample BGC showed Ea (0.12 ev) between BGC and BGS. Our results are similar to those founded by Acros et al., [51], in which Ea was studied as a parameter to predict bioactivity of glasses.

\section{In vitro behavior analysis}

Sample BGS was selected for more in vitro experiments as it involves higher surface area and silicon ion release than other samples. Fig. 8 illustrates the XRD pattern of sample BGS after soaking in SBF during 20 days. The XRD results indicated that the initial sample BGS has amorphous structure but a crystalline phase was formed gradually after soaking the sample in SBF. Only after a day soaking in $\mathrm{SBF}$, the XRD diagram shows the present of peaks at $25.8^{\circ}$ and $31.9^{\circ}$ which corresponding to the (002) and (211) reflection of apatite phase accordingly [42]. The characteristic reflections of hydroxyapatite have been identified clearer for the sample soaked for 20 days.

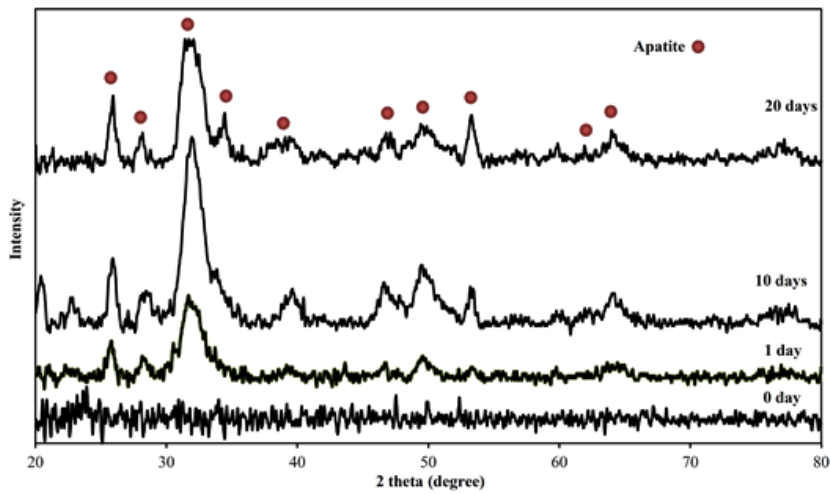

Fig. 8. The XRD pattern of sample BGS after soaking in SBF.

Fig. 9 illustrates the FTIR spectra of sample BGS during soaking in SBF at different time intervals. After a day of immersion of sample BGS in SBF, at 564 and $603 \mathrm{~cm}^{-1}$ the bending mode of $v 4(\mathrm{P}-\mathrm{O}-\mathrm{P})$ band and at $1260 \mathrm{~cm}^{-1}$ the $\mathrm{P}-\mathrm{O}$ asymmetric stretching vibration of $\mathrm{PO}_{4}{ }^{3-}$ in apatite was observed. Furthermore, at first day of soaking in SBF a broad pick was observed at $1500 \mathrm{~cm}^{-1}$ which converts to two separate picks after 20 days of soaking. In a similar study, Mačković considered this pick as adsorbed carbonates on surface $v 3\left(\mathrm{CO}_{3}{ }^{2-}\right)$ [35]. The silica vibrations, $\mathrm{Si}-\mathrm{O}-\mathrm{Si}$ bending, $\mathrm{Si}-\mathrm{O}-\mathrm{Si}$ symmetric stretching and $\mathrm{Si}-\mathrm{O}-\mathrm{Si}$ asymmetric stretching modes are noticed at 464,800 and $1088 \mathrm{~cm}^{-1}$, respectively. In addition, the absorption band at
3430 and $1636 \mathrm{~cm}^{-1}$ were assigned to $\mathrm{OH}$. The FTIR results in agreement with XRD results confirms the formation of apatite just after one-day soaking of the sample BGS in SBF $[53,54]$.

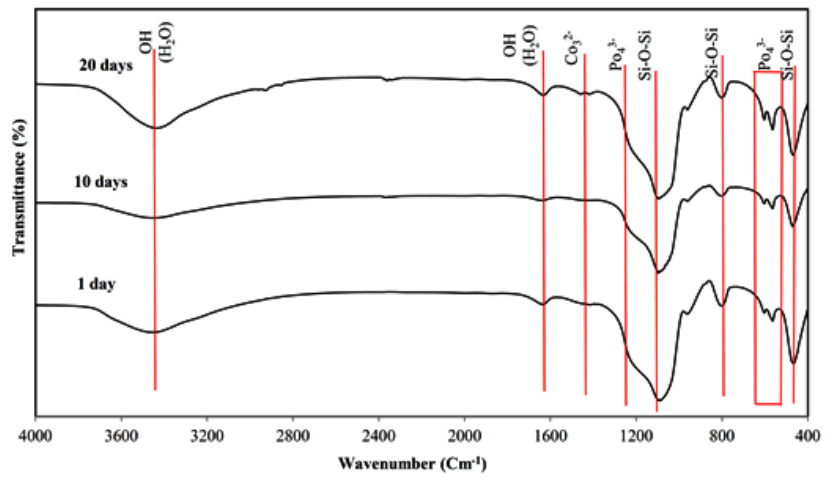

Fig. 9. FTIR spectra of BGS during soaking in SBF.

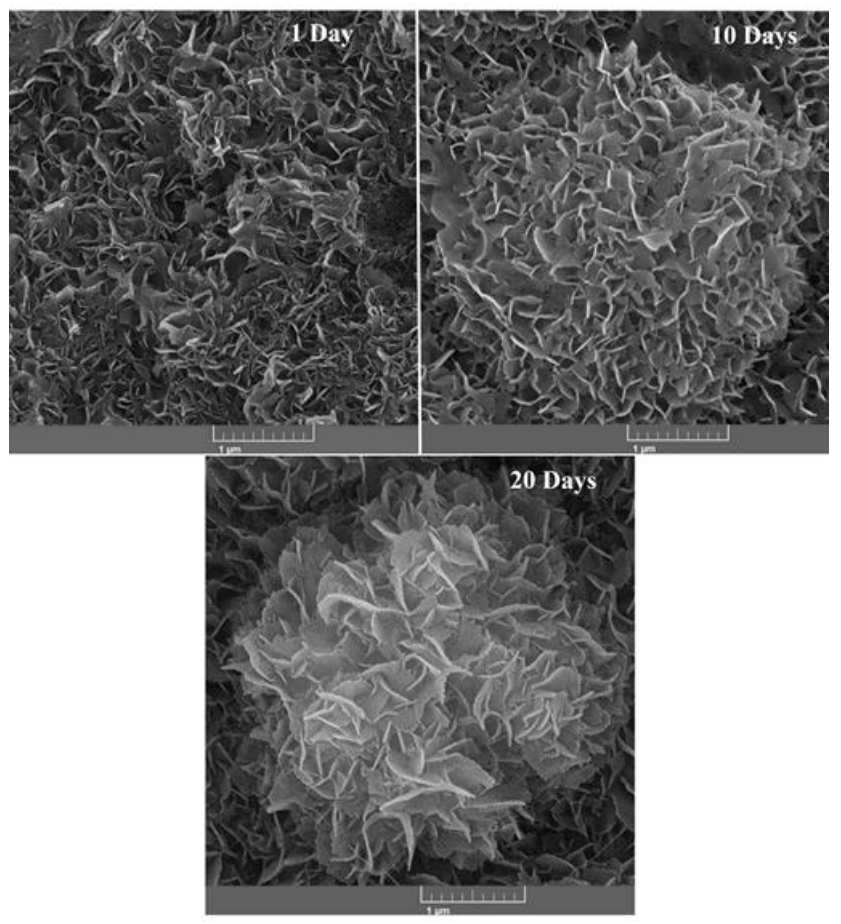

Fig. 10. FE-SEM images of sample BGS after soaking in SBF.

The FE-SEM images of BGS sample after soaking in SBF in different periods of time are displayed in Fig. 10. The SEM images also indicated the formation of hydroxyapatite on the surface of BGS after the first day of soaking. After 10 days, plate-like crystals were found to be more visible on the surface of BGS. Finally, flowers-like microspheres with diameters about $2 \mu \mathrm{m}$ self-assembled from growth of plate-like crystals on the surface of BGS [36]. The evaluation of SEM images in different time intervals indicates that the hydroxyapatite is formed at the first day on the surface of BGS but grown at longer times. Similar studies show the formation of hydroxyapatite phase required at least soaking time of 2 days [13]. Letaief et al., reported that porosity on the surface of glass allows a fast nucleation and therefore rapid apatite growth on its surface. 


\section{Advanced Materials Letters www.vbripress.com/aml}

So, the main factor contributes the crystallization rate of apatite phase on the surface of glass is textural properties [13]. The formation of hydroxyapatite just one day after soaking of the sample in SBF confirms the high specific surface area of BGS plays an important role in the rate of hydroxyapatite formation.

EDS results of both un-soaked and soaked BGS are shown in Fig. 11. The elemental analysis results show, soaking of BGS in the SBF led to a considerable increase in $\mathrm{Ca}$ and $\mathrm{P}$ elements and a sharp decrease in Si element, which are consistent with the formation of hydroxyapatite in Bioglass [37].
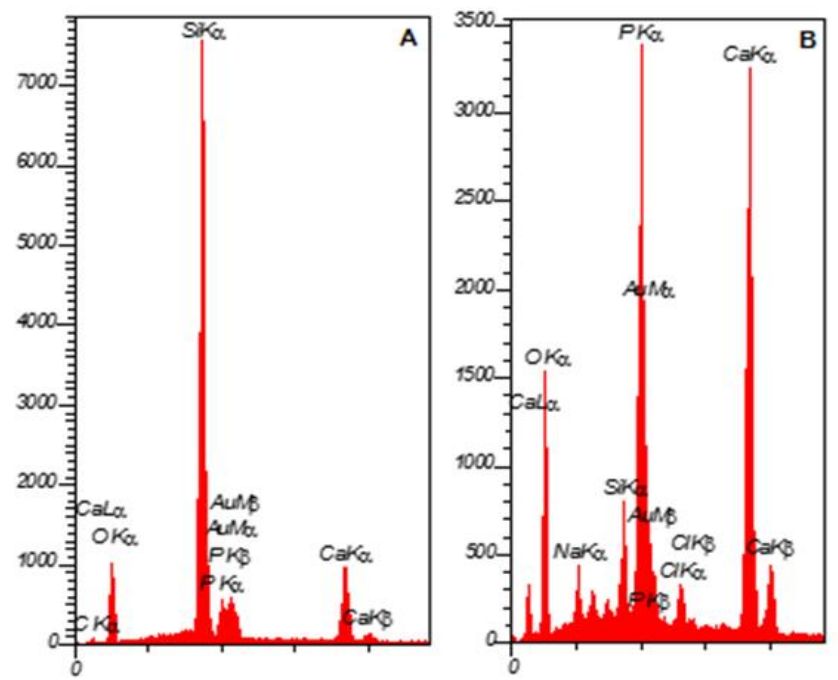

Fig. 11. EDS results of sample BGS before (A) and after (B) soaking in SBF.

\section{Conclusion}

Three mesoporous bioactive glasses were synthesized by using two surfactants, SDS as anionic and Triton X-100 as nonionic surfactant by sol-gel method. All three samples present mesoporous structure as a consequence of sol-gel method. Based on results gained in pervious sections, using anionic surfactant is more effective than nonionic surfactant on increasing surface area. In vitro behavior analysis showed that synthesized glasses have ability to form apatite layer on their surface. After only a day fluting in SBF, apatite layer appears on the surface of sample BGS which confirm its bioactivity.

\section{Keywords}

Bioactive glass, bioactivity, structural properties, tissue engineering.

Received: 01 April 2020

Revised: 10 April 2020

Accepted: 10 April 2020

\section{References}

1. Arcos, D.; Vallet-Regí, M.; Acta Biomaterialia, 2010, 6, 2874.

2. Misra, S.K., et al., Journal of The Royal Society Interface, 2009, rsif20090255.

3. Chen, Q.Z.; Thompson, I.D.; Boccaccini, A.R.; Biomaterials, 2006, 27, 2414.

4. Hench, L.L.; Wilson, J.; Science, 1984, 226, 630.
5. Jones, J.R.; et al., Biomaterials, 2007, 28, 1653.

6. $\mathrm{Fu}, \mathrm{Q}$.; et al., Materials Science and Engineering: C, 2011, 31, 1245.

7. Cannillo, V.; et al., Ceramics International, 2009, 35, 2853.

8. Oliveira, J.; Correia, R.; Fernandes, M.; Biomaterials, 2002, 23, 371.

9. Oonishi, H.; et al., Journal of Biomedical Materials Research, 2000, $51,37$.

10. Hench, L.L.; Andersson, O.; Advanced Series in Ceramics, 1993, 1, 41.

11. Lázaro, G.S.; et al., Journal of Non-Crystalline Solids, 2014, 386, 19.

12. Li, R.; Clark, A.; Hench, L.; Journal of Applied Biomaterials, 1991, 2, 231.

13. Balas, F.; Pérez-Pariente, J.; Vallet-Regí, M.; Relationship between bioactivity and textural parameters in glasses in BioceramicsConference, 1998.

14. Ogino, M.; Ohuchi, F.; Hench, L.L.; Journal of Biomedical Materials Research Part A, 1980, 14, 55.

15. Wu, C.; Chang, J.; Interface Focus, 2012, rsfs20110121.

16. Arcos, D.; et al., Chemistry of Materials, 2009, 21, 1000.

17. Manzano, M.; Vallet-Regí, M.; Journal of Materials Chemistry, 2010, 20, 5593.

18. Vallet-Regí, M.; Balas, F.; Arcos, D.; Mesoporous materials for drug delivery. Angewandte Chemie International Edition, 2007, 46(40), p. 7548-7558.

19. Vallet-Regí, M.; et al., Journal of Materials Chemistry, 2006, 16, 26.

20. Mitsuda, K.; Kimura, H.; Murahashi, T.; Journal of Materials Science, 1989, 24, 413.

21. Ramimoghadam, D.; Hussein, M.Z.B.; Taufiq-Yap, Y.H.; International Journal of Molecular Sciences, 2012, 13, 13275.

22. Frajkorová, F.; et al., Ceramics International, 2015, 41, 9770.

23. Sing, K.S.; Pure and Applied Chemistry, 1985, 57, 603.

24. Gubbins, K.E.; Hysteresis Phenomena in Mesoporous Materials. 2009.

25. Lowell, S.; et al., Characterization of porous solids and powders: surface area, pore size and density. Vol. 16. 2012: Springer Science $\&$ Business Media.

26. Mitsuda, K.; Kimura, H.; Murahashi, T.; Journal of Materials Science, 1989, 24, 413.

27. Ramimoghadam, D.; Hussein, M.Z.B.; Taufiq-Yap, Y.H.; International Journal of Molecular Sciences, 2012, 13, 13275.

28. Frajkorová, F.; et al., Ceramics International, 2015, 41, 9770.

29. Sing, K.S.; Pure and Applied Chemistry, 1985, 57, 603.

30. Gubbins, K.E.; Hysteresis Phenomena in Mesoporous Materials. 2009

31. Lowell, S.; et al., Characterization of porous solids and powders: surface area, pore size and density. Vol. 16. 2012: Springer Science $\&$ Business Media.

32. ElBatal, H. A.; et al. Materials Chemistry and Physics, 2003, 80, 599.

33. Hench, L. L.; Wilson, J.; Biomaterials, 1984, 5, 11.

34. Holland L.; The properties of glass surfaces. New York: John, Wiley \& Sons, 1964, p142.

35. Mačković, M.; et al. Journal of Nanoparticle Research, 2012, 14, 966.

36. Xu, Z.; et al., RSC Advances, 2016, 6, 76426.

37. Ramimoghadam, D.; Hussein, M.Z.B.; Taufiq-Yap, Y.H.; International Journal of Molecular Sciences, 2012, 13, 13275.

38. Prabhu, M.; et al. BioMed Research International, 2014, 2014.

39. Stanley, R.; Samson Nesaraj, A.; International Journal of Applied Science and Engineering, 2014, 12, 9.

40. Singho, Noorsaiyyidah Darman; Rafie Johan, Mohd; Int. J. Electrochem. Sci., 2012, 7, 5604.

41. Gorji, B.; et al. Journal of Applied Chemical Research, 2012, 6, 22.

42. Letaief, Nouha, et al. Microporous and Mesoporous Materials, 2014, 195, 102.

43. Zana, Raoul, et al. Langmuir, 1999, 15, 2603.

44. Tabia, Zakaria, et al. RSC Advances, 2019, 9, 12232.

45. López-Noriega, A.; et al. Chemistry of Materials, 2006, 18, 3137.

46. Cerruti; Marta; David Greenspan; Kevin Powers. Biomaterials, 2005, 26, 1665.

47. Huo, Qisheng, et al. Chemistry of Materials, 1994, 6, 1176

48. Wan, Ying, Dongyuan Zhao; Chemical Reviews, 2007, 107, 2860. 


\section{Advanced}

49. Iler, R. K.; "The Chemistry of Silica: solubility, polymerization, colloid and surface and surface properties, and biochemistry." 1979, 867.

50. Han, Lu; Shunai Che.; Chemical Society Reviews, 2013, 42, 3740.

51. Arcos, D.; Greenspan, D. C.; Vallet-Regí, M.; Journal of Biomedical Materials Research Part A: An Official Journal of The Society for Biomaterials, The Japanese Society for Biomaterials, and The Australian Society for Biomaterials and the Korean Society for Biomaterials, 2003, 65, 344

52. Gerhardt; Lutz-Christian; Aldo R. Boccaccini; Materials, 2010, 3, 3867.

53. Notingher, I.; Jones, J. R.; Verrier, S.; Bisson, I.; Embanga, P.; Edwards, P.; Polak, J. M.; Hench, L. L.; Journal of Spectroscopy, 2003, 17, 275 .

54. Adams, Luqman A.; Enobong R. Essien; Rafiu O. Shaibu; Aderemi Oki; New Journal of Glass and Ceramics, 2013, 3, 11.

55. Kumar, Balmiki; Kulanthaivel, Senthilguru; Mondal, Animesh; Mishra, Smruti; Banerjee, Biplab; Bhaumik, Asim; Banerjee, Indranil; Giri, Supratim; Colloids and Surfaces B: Biointerfaces, 2017, 150, 352 .

56. Das, Swapan K.; Bhunia, Manas K.; Chakraborty, Debrup; Rahman Khuda-Bukhsh, Anisur; Bhaumik, Asim; Chemical Communications, 2012, 48, 2891. 